\title{
Pulmonary gas exchange and acid-base state at 5,260 m in high-altitude Bolivians and acclimatized lowlanders
}

\author{
PETER D. WAGNER, ${ }^{1}$ MAURICIO ARAOZ, ${ }^{2}$ ROBERT BOUSHEL,${ }^{3}$ JOSÉ A. L. CALBET,${ }^{3}$ \\ BIRGITTE JESSEN, ${ }^{3}$ GÖRAN RÅDEGRAN,${ }^{3}$ HILDE SPIELVOGEL, ${ }^{2}$ \\ HANS SØNDEGAARD, ${ }^{3}$ HARRIETH WAGNER, ${ }^{1}$ AND BENGT SALTIN ${ }^{3}$ \\ ${ }^{3}$ Copenhagen Muscle Research Centre, Copenhagen, Denmark 2200; ${ }^{2}$ Instituto Boliviano \\ de Biologia de Altura, Bolivia; and ${ }^{1}$ Division of Physiology, Department of \\ Medicine, University of California, San Diego, La Jolla, California 92093
}

Received 30 January 2001; accepted in final form 9 November 2001

\begin{abstract}
Wagner, Peter D., Mauricio Araoz, Robert Boushel, José A. L. Calbet, Birgitte Jessen, Göran Rådegran, Hilde Spielvogel, Hans Søndegaard, Harrieth Wagner, and Bengt Saltin. Pulmonary gas exchange and acid-base state at 5,260 $\mathrm{m}$ in high-altitude Bolivians and acclimatized lowlanders. J Appl Physiol 92: 1393-1400, 2002. First published November 16, 2001; 10.1152/japplphysiol.00093.2001.Pulmonary gas exchange and acid-base state were compared in nine Danish lowlanders (L) acclimatized to 5,260 m for 9 wh and seven native Bolivian residents (N) of La Paz (altitude $3,600-4,100 \mathrm{~m}$ ) brought acutely to this altitude. We evaluated normalcy of arterial $\mathrm{pH}$ and assessed pulmonary gas exchange and acid-base balance at rest and during peak exercise when breathing room air and $55 \% \mathrm{O}_{2}$. Despite $9 \mathrm{wk}$ at $5,260 \mathrm{~m}$ and considerable renal bicarbonate excretion (arterial plasma $\mathrm{HCO}_{3}{ }^{-}$concentration $=15.1 \mathrm{meq} / \mathrm{l}$ ), resting arterial pH in L was $7.48 \pm 0.007$ (significantly greater than 7.40). On the other hand, arterial $\mathrm{pH}$ in $\mathrm{N}$ was only $7.43 \pm$ 0.004 (despite arterial $\mathrm{O}_{2}$ saturation of $77 \%$ ) after ascent from 3,600-4,100 to 5,260 $\mathrm{m}$ in $2 \mathrm{~h}$. Maximal power output was similar in the two groups breathing air, whereas on 55\% $\mathrm{O}_{2}$ only $\mathrm{L}$ showed a significant increase. During exercise in air, arterial $\mathrm{PCO}_{2}$ was 8 Torr lower in $\mathrm{L}$ than in $\mathrm{N}(P<0.001)$, yet $\mathrm{PO}_{2}$ was the same such that, at maximal $\mathrm{O}_{2}$ uptake, alveolar-arterial $\mathrm{PO}_{2}$ difference was lower in $\mathrm{N}(5.3 \pm 1.3$ Torr) than in $\mathrm{L}(10.5 \pm 0.8$ Torr $), P=0.004$. Calculated $\mathrm{O}_{2}$ diffusing capacity was $40 \%$ higher in $\mathrm{N}$ than in $\mathrm{L}$ and, if referenced to maximal hyperoxic work, capacity was $73 \%$ greater in N. Buffering of lactic acid was greater in $\mathrm{N}$, with $20 \%$ less increase in base deficit per millimole per liter rise in lactate. These data show in $\mathrm{L}$ persistent alkalosis even after $9 \mathrm{wk}$ at $5,260 \mathrm{~m}$. In $\mathrm{N}$, the data show 1 ) insignificant reduction in exercise capacity when breathing air at $5,260 \mathrm{~m}$ compared with breathing $55 \% \mathrm{O}_{2} ; 2$ ) very little ventilatory response to acute hypoxemia (judged by arterial $\mathrm{pH}$ and arterial $\mathrm{PCO}_{2}$ responses to hyperoxia); 3) during exercise, greater pulmonary diffusing capacity than in $\mathrm{L}$, allowing maintenance of arterial $\mathrm{PO}_{2}$ despite lower ventilation; and 4) better buffering of lactic acid. These results support and extend similar observations concerning adaptation in lung function in these and other high-altitude native groups previously performed at much lower altitudes.
\end{abstract}

hypoxia; ventilation; acid-base balance; diffusing capacity

Address for reprint requests and other correspondence: P. D. Wagner, Div. of Physiology, Univ. of California, San Diego, 9500 Gilman Dr., MC 0623A, La Jolla, CA 92093 (E-mail: pdwagner @ucsd.edu).
THE REMARKABLE ABILITIES of high-altitude natives to perform work at altitude are well known (15), and much research has been carried out to understand the physiological basis of this phenomenon. Considerable attention has been focused on the lungs, and several studies point to differences in lung structure and function between high-altitude natives and lowlanders of Tibet (23), South America (15), and even the United States (6). Some of the differences appear to be inherited adaptations consequent to generations of living at altitude. Others may result from individual lifelong or at least long-term high-altitude residence, whereas others may occur over the short term of days to weeks. Principal observations are that lung volumes are greater than predicted by sea-level tables $(15,23)$ and that diffusing capacity is also elevated $(4-6,9,15)$. Reduced ventilatory response to hypoxia is often $(6,15)$ but not always (22) seen, resulting in arterial $\mathrm{PCO}_{2}$ values that are higher in high-altitude natives than in lowlanders. Despite this, arterial oxygenation is defended during exercise by a smaller alveolar-arterial $\mathrm{PO}_{2}$ difference $\left[(\mathrm{A}-\mathrm{a}) \mathrm{PO}_{2}\right]$ in natives compared with lowlanders, such that arterial $\mathrm{O}_{2}$ saturation is similar between groups (6) or even higher in natives (23). These findings have mostly been obtained at or below 4,000 m.

During a recent expedition to Mt. Chacaltaya (altitude 5,260 m) near La Paz, Bolivia, we took the opportunity to further explore differences in pulmonary function between South American high-altitude natives and lowlanders. This expedition was focused primarily on circulatory and skeletal muscle changes with acclimatization, and this required arterial blood sampling at rest and during exercise. Thus, whereas pulmonary function was not a primary target of the expedition, the gas-exchange and acid-base differences seen in the lowlanders compared with natives were substantial, prompting their description in the present report. What this study offered beyond those described above

The costs of publication of this article were defrayed in part by the payment of page charges. The article must therefore be hereby marked "advertisement" in accordance with 18 U.S.C. Section 1734 solely to indicate this fact. 
was a side-by-side comparison of lowlanders and Andean natives using identical methods and with direct arterial blood sampling not available in Schoene et al.'s work (15) in subjects of similar population ancestry. An unusual additional aspect of the present study was that the lowlanders had acclimatized for $9 \mathrm{wk}$ at the chosen altitude before measurements. Most acclimatization studies have not allowed such a long period at a single altitude but have followed subjects as they inexorably continued to ascend, preventing attainment of steady-state conditions at any point. Moreover, the studies of Dempsey et al. (6), Zhuang et al. (23), and Schoene et al. (15) were all carried out at substantially lower altitudes $(3,100,3,658$, and $3,900 \mathrm{~m}$, respectively) than the present effort, which took place at $5,260 \mathrm{~m}$. In the present study, measurements were made both at rest and during exercise and addressed the following questions: 1) Does $9 \mathrm{wk}$ at this constant high altitude permit complete $\mathrm{pH}$ normalization (i.e., restoration of arterial $\mathrm{pH}$ to near 7.40) in lowlanders? 2) Does acute hypoxia in natives (who were necessarily transported on the day of the study from La Paz, altitude $3,600-4,100 \mathrm{~m}$, to $5,260 \mathrm{~m}$ ) produce a substantial additional stimulus to breathing at rest or during exercise, and a measurable reduction in exercise capacity as would occur for lowlanders moving between these altitudes? 3) Is arterial oxygenation during exercise still defended in natives at 5,260 $\mathrm{m}$ as appears to be the case at lower altitudes, and, if so, are the physiological mechanisms similar to those described above in prior studies [higher diffusing capacity and lower (A-a) $\left.\mathrm{PO}_{2}\right]$ ? 4) Is arterial acid-base regulation similar in natives and acclimatized lowlanders?

\section{METHODS}

Subjects. This study used nine lowlanders from Denmark and seven Bolivian natives of mixed European and Amerindian population ancestry, lifetime residents of $\mathrm{La} \mathrm{Paz}$ at between 3,600 and 4,100 m. All provided informed consent to protocols approved by both Danish and Bolivian ethical committees (Copenhagen-Fredericksberg Ethical Review Committee and Comité de Etica del Colegio Médico de La Paz). Anthropometric and key additional physiological attributes are given in Table 1 . All 16 subjects were healthy, habitually active, and nonsmokers. The Danes were physically active college students with an interest in outdoor recreation, whereas the Bolivians indulged in a variety of regular social activities including soccer. Only one Bolivian was a trained athlete (marathon runner). There were small differences in age (Bolivians 3 yr older, $P=0.05$ ) and height (Bolivians 12 cm shorter, $P=0.01$ ), but weight and body mass index were not significantly different. Both hemoglobin concentration and hemoglobin $\mathrm{PO}_{2}$ at 50\% saturation of hemoglobin $\left(\mathrm{P}_{50}\right)$ were similar in the two groups (Table 1) as well. Note from Table 1 that maximal cycling power output (that is, highest power sustainable for the $5 \mathrm{~min}$ required for stabilization and data collection) and associated $\mathrm{O}_{2}$ uptake $\left(\mathrm{V}_{2}\right)$ when breathing ambient air at 5,260 $\mathrm{m}$ were also similar between groups.

The lowlanders spent $9 \mathrm{wk}$ at 5,260 m, and the studies were done in the last week. The lowlanders all undertook two brief (2-3 day) climbs of neighboring $6,000 \mathrm{~m}$ peaks (one in week 2 and one in week 7) and a 1-day recreational bicycle descent to 2,000 $\mathrm{m}$ in week 6 . Otherwise, they all remained at Mt. Chacaltaya at $5,260 \mathrm{~m}$ for the entire period. None displayed evidence of high-altitude pulmonary or cerebral edema at any time.

Subject preparation. The protocols were designed to simultaneously address several questions, many of which were well beyond those pertaining to pulmonary function, and thus required several catheters whose purposes are unrelated to the present report. Under local anesthesia and with sterile technique, catheters were placed in a femoral vein (94-030-2.5F TD probe, Edwards Edslab, Baxter, Irvine, CA) and artery (18-gauge Hydrocath, Ohmeda, Swindon, UK) to enable both blood sampling and measurements of femoral venous blood flow by thermodilution (1). A peripheral venous catheter was placed in an antecubital vein in the lowlanders, to be used for indocyanine green dye injection for cardiac output measurements. Cardiac output was also measured in the high-altitude natives, but with the use of an acetylene uptake method (2) to avoid additional catheters and blood sampling unacceptable to the subjects.

Subjects were then seated on a cycle ergometer (Monark $824 \mathrm{E}$, Varberg, Sweden) and fitted with a mouthpiece and nose clip in standard fashion to enable measurements of ventilation, $\mathrm{V}_{2}$, and $\mathrm{CO}_{2}$ production $\left(\dot{\mathrm{V}}_{\mathrm{CO}_{2}}\right)$ from expired gas (using ParvoMedics True Max 2400, Consentius Technologies, UT). An electrocardiogram monitor was attached with standard leads to record heart rate and oversee rhythm.

Protocol. Both lowlanders and high-altitude natives undertook identical protocols as follows. After resting measurements, a submaximal work rate averaging $120 \mathrm{~W}$ was selected, and subjects pedaled at this power output for $10 \mathrm{~min}$, with duplicate measurements made in the final $5 \mathrm{~min}$. After

Table 1. Anthropometric and exercise capacity characteristics of high-altitude natives and of lowlanders after acclimatization

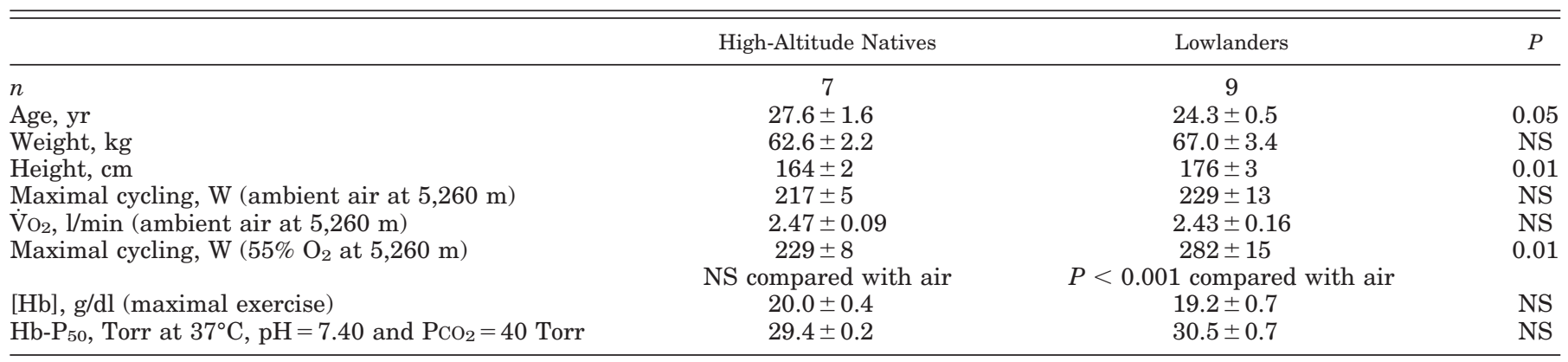

Values are means $\pm \mathrm{SE} ; n$, no. of subjects. $\dot{\mathrm{V}}_{2}, \mathrm{O}_{2}$ uptake; [Hb], hemoglobin concentration; $\mathrm{P}_{50}, \mathrm{PO}_{2}$ at $50 \%$ saturation of hemoglobin. 
a 10-min rest, subjects again cycled at $120 \mathrm{~W}$ for $2 \mathrm{~min}$, after which work rate was rapidly raised to the previously determined individual peak rate known to be sustainable for 5 min. During the final $2 \mathrm{~min}$ of this 5 -min period, duplicate measurements were again obtained. With subjects still pedaling, a higher work rate was imposed if subjects indicated ability to continue, and measurements were repeated within 2 min. When each subject could increment work rate no further, the inspired gas was switched from ambient air [barometric pressure $=408$ Torr; inspiratory $\mathrm{Po}_{2}\left(\mathrm{PI}_{\mathrm{O}_{2}}\right)=75$ Torr] to $\sim 55 \% \mathrm{O}_{2}\left(\mathrm{PI}_{\mathrm{O}_{2}}=195-200\right.$ Torr $)$ while the subject continued to pedal. After $2 \mathrm{~min}$, another set of measurements was taken, and work rate was further incremented individually if tolerated to attain a new peak power output. A final set of measurements was then obtained under these conditions.

It should be noted that the above was actually a subset of the entire day's protocol. Those elements that pertained to questions other than lung-related issues are not described here. These include submaximal and maximal exercise runs using single-leg knee extensor effort and also cycle exercise after parasympathetic nervous system blockade (reported elsewhere, Ref. 3). The knee extensor runs were done before those described for the present study and were separated from the present cycle exercise by an hour of rest, but the parasympathetic blockade experiments were always done after the present study had been completed.

Measurements. Other than $\dot{\mathrm{V}}_{2}, \dot{\mathrm{V}}_{\mathrm{CO}_{2}}$, and ventilation, the principal data were obtained from arterial blood samples and consisted of $\mathrm{PO}_{2}, \mathrm{PCO}_{2}$, and $\mathrm{pH}$ (Radiometer ABL5); saturation and hemoglobin concentration (Radiometer OSM3); and plasma lactate levels (ABL5). All values of $\mathrm{PO}_{2}, \mathrm{PCO}_{2}$, and $\mathrm{pH}$ were corrected to blood temperature measured by the femoral venous catheter thermistor. Cardiac output was measured in lowlanders by indocyanine green dye dilution with injection in a peripheral (antecubital) vein and femoral arterial sampling (3). In natives, a noninvasive method for measuring cardiac output was chosen to minimize catheter placements and blood loss. We used the acetylene uptake method (2) and employed the SensorMedics $\mathrm{VO}_{2}$ max system (SensorMedics, Yorba Linda, CA) to measure acetylene (and an insoluble reference gas, methane) concentrations at the mouth. This system also measures ventilation and $\mathrm{O}_{2}$ and $\mathrm{CO}_{2}$ concentrations and so provided all of the input data required for calculation of cardiac output as explained in Barker et al.'s paper (2). Without any equipment to measure acetylene solubility, we assumed for all subjects an average blood:gas partition coefficient of 0.8 on the basis of Barkers' results and an estimate from Jibelian et al. (10) of the contribution of the higher than sea-level hemoglobin concentration.

Calculations. Oxygen-diffusing capacity of the lungs $\left(\mathrm{DL}_{2}\right)$ was not directly measured at rest or during exercise. However, a value for $\mathrm{DL}_{\mathrm{O}_{2}}$ could be calculated from the measured blood-gas data by use of a numerical forward-integration algorithm (19) as follows. First, by using the measured pulmonary $\dot{\mathrm{V}}_{2}$, cardiac output, and arterial $\mathrm{O}_{2}$ concentrations, mixed venous $\mathrm{O}_{2}$ levels were computed for each subject. Similar calculations were performed for $\mathrm{CO}_{2}$. Alveolar $\mathrm{PO}_{2}$ was also determined for each subject by using the alveolar gas equation and taking alveolar $\mathrm{PCO}_{2}$ to be equal to arterial $\mathrm{PCO}_{2}$. Between these venous and alveolar values for $\mathrm{PO}_{2}$ and $\mathrm{PCO}_{2}$, a value of $\mathrm{DL}_{\mathrm{O}_{2}}$ was found (by using the numerical integration procedure in an iterative manner) that predicted the measured arterial $\mathrm{PO}_{2}$ and $\mathrm{PCO}_{2}$ for each subject. The key assumption, made for both subject groups, was that all of the (A-a) $\mathrm{PO}_{2}$ found during exercise at $5,260 \mathrm{~m}$ was due to diffu- sion limitation and none was caused by ventilation-perfusion inequality. The diffusing capacity was therefore calculated by assuming a homogeneous lung and, as a result, is a conservative lowest estimate. This assumption is seen in DISCUSSION.

Analysis of data. The principal objective of this study was to compare several elements of exercise performance between high-altitude natives and acclimatized lowlanders. This was done by two-way ANOVA (subjects $\times$ exercise levels, the latter by repeated measures) followed by unpaired $t$-tests comparing subject groups at any exercise level when ANOVA indicated significant group effects. Data in figures and tables are given as means $\pm \mathrm{SE}$ because the major interest is in mean differences between the two subject groups.

\section{RESULTS}

Resting gas exchange. Lowlanders hyperventilated compared with natives. Figure 1 shows resting arterial $\mathrm{PO}_{2}$, arterial $\mathrm{PCO}_{2}$, and $(\mathrm{A}-\mathrm{a}) \mathrm{Po}_{2}$ in both groups. $\mathrm{Po}_{2}$ was 8 Torr higher $(50.0 \pm 1.1$ vs. $42.1 \pm 0.7, P<0.001)$ and $\mathrm{PCO}_{2} 9$ Torr lower $(21.1 \pm 0.9$ vs. $30.0 \pm 0.3, P<$ 0.001) in lowlanders. However, in both groups, (Aa) $\mathrm{PO}_{2}$ was similar and not different from zero.

Arterial pH was significantly higher in the lowlanders at $7.48 \pm 0.007 \mathrm{vs} .7 .43 \pm 0.004$ in the natives, $P<0.001$, whereas bicarbonate levels were lower $(15.1 \pm 0.5 \mathrm{meq} / \mathrm{l}$ in lowlanders; $19.4 \pm 0.3 \mathrm{meq} / \mathrm{l}$ in natives, $P<0.001)$. As a result, calculated base excess was more negative in the lowlanders $(-5.6$ vs. -3.5 meq/l respectively, $P<0.001)$. Resting arterial blood lactate levels were similar (1.5 and $1.4 \mathrm{mmol} / \mathrm{l}, P$ not significant). The lowlanders showed greater perturbation of acid-base balance than the natives. It is remarkable that in the natives, despite rapid ascent from $3,600-4,100$ to $5,260 \mathrm{~m}$ over $2 \mathrm{~h}$ and an arterial $\mathrm{O}_{2}$ saturation of $77 \%$, arterial $\mathrm{pH}$ was 7.43 , hardly different from a normal pH of 7.40 or from values of resting arterial $\mathrm{pH}$ of 7.41 reported previously in such natives at $3,600 \mathrm{~m}(17)$.

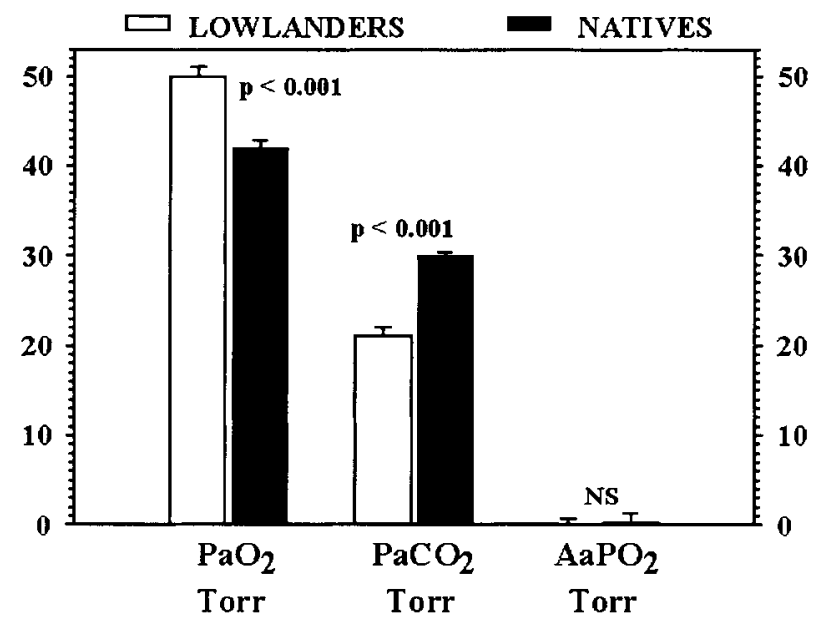

Fig. 1. Resting arterial $\mathrm{Po}_{2}\left(\mathrm{~Pa}_{2}\right)$ and $\mathrm{PCO}_{2}\left(\mathrm{~Pa}_{\mathrm{CO}_{2}}\right)$ and alveolararterial $\mathrm{PO}_{2}$ difference [(A-a) $\left.\mathrm{PO}_{2}\right]$ at $5,260 \mathrm{~m}$ in subjects breathing ambient air. Lowlanders hyperventilate compared with high-altitude natives, but $(\mathrm{A}-\mathrm{a}) \mathrm{PO}_{2}$ is essentially zero in both groups. Values are means $\pm \mathrm{SE}$ 

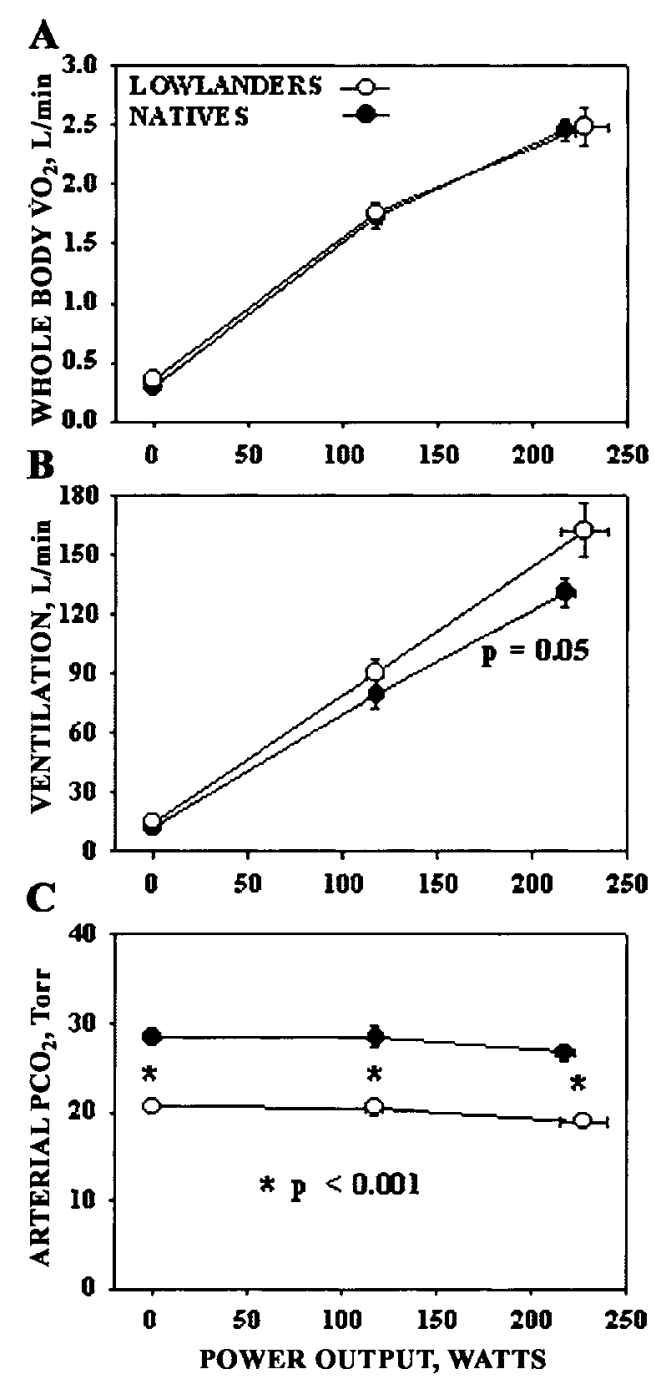

Fig. 2. $\mathrm{O}_{2}$ uptake $\left(\dot{\mathrm{V}}_{2}\right)$, ventilation, and arterial $\mathrm{PCO}_{2}$ during exercise at $5,260 \mathrm{~m} . A$ : $\dot{\mathrm{V}}_{2}$ increases similarly in both groups to indistinguishable maximal values. $B$ : compared with natives, lowlanders continue to hyperventilate throughout exercise. $C$ : arterial $\mathrm{PCO}_{2}$ is $\sim 8$ Torr lower in lowlanders at rest and throughout the range of exercise. Values are means $\pm \mathrm{SE}$.

Ventilatory response to exercise. Figure $2 A$ shows that $\mathrm{O}_{2}$ consumption at rest, submaximal exercise, and maximal exercise while breathing ambient air at 5,260 $\mathrm{m}$ was essentially identical in the two groups, allowing a comparison that is not encumbered by questions of relative vs. absolute work rates nor by differences in efficiency of $\mathrm{O}_{2}$ utilization. Figure $2 B$ shows that lowlanders continued to mount a greater ventilatory response than natives throughout exercise. At maximal $\dot{\mathrm{V}}_{2}\left(\dot{\mathrm{V}}_{2}\right.$ max $)$, minute ventilation was $163 \mathrm{l} / \mathrm{min}$ in the lowlanders vs. $131 \mathrm{l} / \mathrm{min}$ in the natives, a difference of $24 \%, P=0.05$. Not surprisingly, arterial $\mathrm{PCO}_{2}$ remained lower in the lowlanders throughout exercise as shown in Fig. $2 C$. At $\dot{V}_{\mathrm{O}_{2}}$ max, arterial $\mathrm{PCO}_{2}$ was 7.4 Torr lower in the lowlanders (19.3 vs. $26.7, P<0.001)$. Arterial $\mathrm{PCO}_{2}$ fell slightly from rest to exercise in both groups (by 2 Torr in lowlanders and 3 Torr in natives, $P$ not significant).
These differences in ventilation at $\dot{\mathrm{V}}_{2}$ max occurred in the face of identical arterial $\mathrm{Po}_{2}$ [45.6 (lowlanders) and 46.0 Torr (natives)] and $\mathrm{O}_{2}$ saturation [72.1 (lowlanders) and $72.3 \%$ (natives)], an arterial $\mathrm{pH}$ that was higher in the lowlanders ( 7.37 vs. $7.33, P=0.04$ ), and an arterial blood lactate concentration that was lower in the lowlanders (8.7 vs. $11.5 \mathrm{mmol} / \mathrm{l}, P=0.04$ ).

Comparing arterial $\mathrm{PCO}_{2}$ values during peak exercise in air and (at the same power output) in $55 \% \mathrm{O}_{2}$ provides additional insight into the ventilatory responsiveness to hypoxia. Recall that, during air breathing, both maximal cycling power output and arterial $\mathrm{Po}_{2}$ were similar in the two groups. In the natives, arterial $\mathrm{PCO}_{2}$ rose $6.4 \%$ from $26.7 \pm 1.0$ to $28.4 \pm 0.8$ Torr, $P=$ 0.02 . In the lowlanders, $\mathrm{PCO}_{2}$ rose $22.8 \%$ from $19.3 \pm$ 0.8 to $23.7 \pm 0.8$ Torr, $P<0.001$. The relative increase in $\mathrm{PCO}_{2}$ (and therefore fall in alveolar ventilation) was thus 3.6-fold greater in lowlanders than in natives when hypoxia was eliminated.

Arterial oxygenation and diffusing capacity during exercise. With note taken of a similar cardiac output response to exercise (Fig. $3 A$ ), important to diffusion equilibration, arterial $\mathrm{PO}_{2}$ during exercise was not different between groups (Fig. 3B). This contrasts with the higher $\mathrm{PO}_{2}$ in lowlanders at rest and occurred despite the substantial differences in ventilation shown in Fig. 2. Arterial $\mathrm{O}_{2}$ saturation followed arterial $\mathrm{PO}_{2}$ (Fig. $3 C$ ), resulting in similar values for arterial $\mathrm{O}_{2}$ concentration (not shown).

With the lower arterial $\mathrm{PCO}_{2}$ yet similar $\mathrm{Po}_{2}$ during exercise, (A-a) $\mathrm{PO}_{2}$ was higher in the lowlanders (Fig. $3 D$ ). Although the absolute differences are not large, they occurred on the steep region of the $\mathrm{O}_{2}$-hemoglobin dissociation curve and thus are important for $\mathrm{O}_{2}$ transport.

$\mathrm{O}_{2}$ diffusing capacity calculated during maximal exercise was $40 \%$ lower in the lowlanders [119 \pm 6 $\mathrm{ml} /(\mathrm{min} \cdot$ Torr $)]$ than in the natives $[167 \pm 15 \mathrm{ml} /$ (min $\cdot$ Torr $)], P=0.01$.

Acid-base balance at rest and during exercise. During maximal exercise, arterial $\mathrm{pH}$ fell from resting levels by similar amounts in the two groups (7.48 to 7.37 in the lowlanders, a difference of $0.11 ; 7.43$ to 7.33 in the natives, a difference of 0.10 ). Although arterial $\mathrm{PCO}_{2}$ values also fell by similar amounts ( 2 and 3 Torr, respectively), there was a significant difference in the arterial blood lactate concentrations: $8.7 \pm 0.8 \mathrm{mmol} / \mathrm{l}$ in lowlanders and $11.5 \pm 1.0 \mathrm{mmol} / \mathrm{l}$ in natives, $P=$ 0.04 . Despite the lower blood lactate levels, calculated base deficit was not smaller in the lowlanders. In fact, base deficit was $12.0 \pm 0.5 \mathrm{meq} / \mathrm{l}$ compared with $10.7 \pm$ 0.7 in the natives. Figure 4 brings out these differences in the relationship between base deficit and lactate levels for the two groups. The scatter about the regression lines comes mostly from differences between subjects in each group, given that individual regressions all had correlation coefficients of $\geq 0.8$. A comparison of the slopes and intercepts of the base deficit-lactate relationship revealed that both the slope and intercept were higher in the lowlanders $(P<0.001$ each). In particular, the slope was $20 \%$ higher in the lowlanders 
$\mathbf{A}$
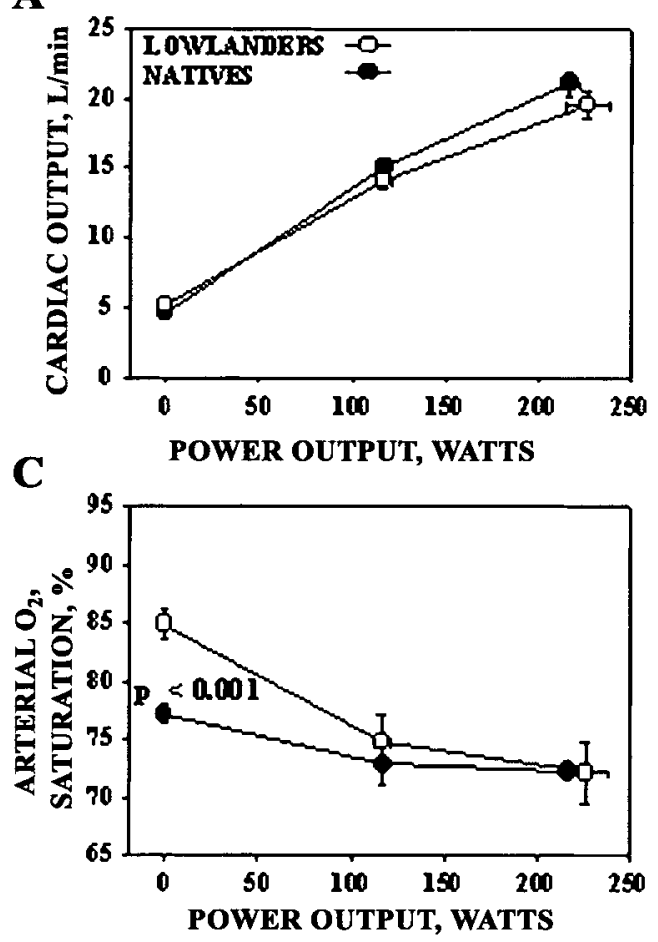

B

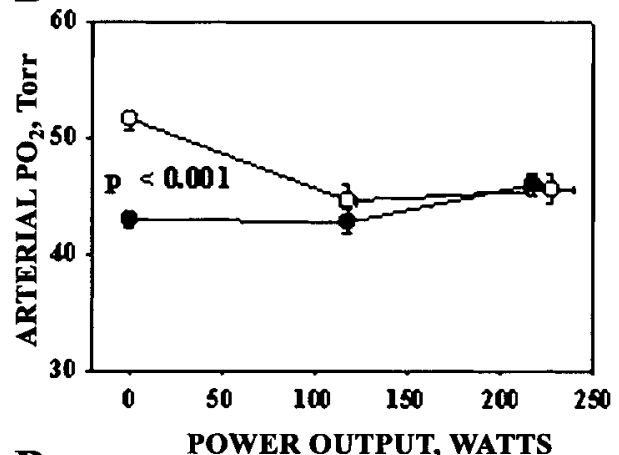

D

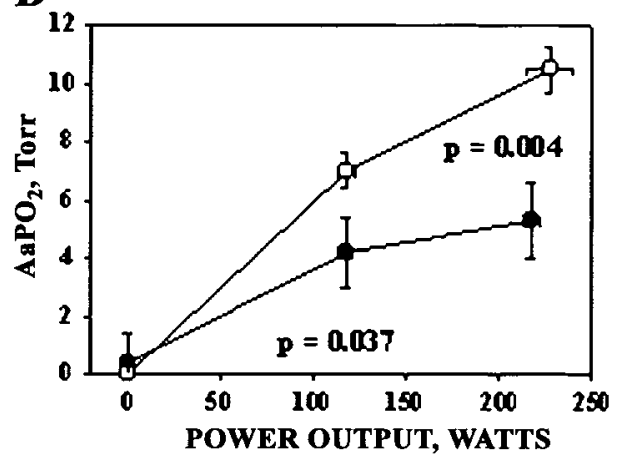

Fig. 3. Cardiac output and gas exchange during exercise at $5,260 \mathrm{~m}$. A: cardiac output responses to exercise are similar in the 2 groups. $B$ : arterial $\mathrm{PO}_{2}$, higher in lowlanders at rest, falls with exercise to levels seen in natives in whom $\mathrm{PO}_{2}$ is maintained. $C$ : arterial $\mathrm{O}_{2}$ saturation in both groups generally follows $\mathrm{PO}_{2}$ but with a slight decrease during exercise because of rightward shifts in the $\mathrm{O}_{2}$ dissociation curve. $D$ : (A-a) $\mathrm{PO}_{2}$ increases with exercise in both groups, but more so in lowlanders. Values are means $\pm \mathrm{SE}$.
$(0.97 \pm 0.02 \mathrm{meq} / \mathrm{mmol}$ compared with $0.81 \pm 0.03 \mathrm{in}$ the natives), implying less ability to buffer lactic acid during exercise, despite the similarity in hemoglobin concentrations (Table 1).

\section{DISCUSSION}

The discussion corresponds to the four questions laid out in the introduction.

Rate of acclimatization in lowlanders at altitude. This study shows that, even after $9 \mathrm{wk}$ at an altitude of $5,260 \mathrm{~m}$, resting arterial $\mathrm{pH}$ is still alkaline (7.48), despite considerable renal bicarbonate excretion.

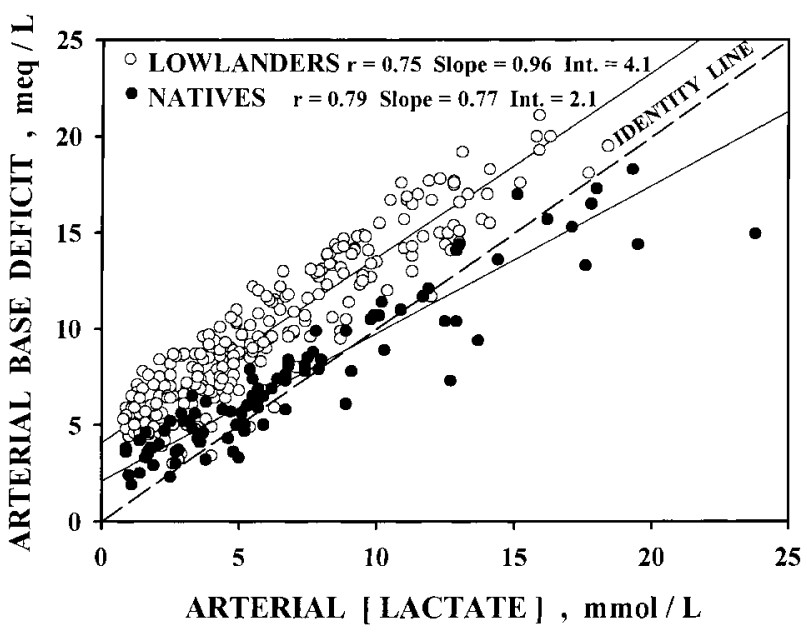

Fig. 4. Relationship between arterial lactate concentration ([lactate]) levels and base deficit in all subjects. Both the slope and intercept are higher in lowlanders, indicating less capacity to buffer lactic acid during exercise.
These results contrast with those of Dempsey et al. (6), in which resting arterial $\mathrm{pH}$ was 7.42 for both sojourners and natives despite the latter having acclimatized for less time (4-45 days). However, this was at 3,100 $\mathrm{m}$, substantially lower than in Bolivia. That arterial $\mathrm{pH}$ eventually normalizes at $5,260 \mathrm{~m}$ is suggested by the present native data. Their $\mathrm{pH}$ was 7.43 despite having ascended from $\mathrm{La} \mathrm{Paz}\left(3,600-4,000 \mathrm{~m}, \mathrm{PI}_{\mathrm{O}_{2}}\right.$ of 95 Torr) to Chacaltaya (5,260 m, $\mathrm{PI}_{\mathrm{O}_{2}}$ of 75 Torr) in just $2 \mathrm{~h}$ and thus having been acutely exposed to significantly greater hypoxia than at their altitude of residence. The data of Vincent et al. (17) further support this conclusion: Arterial $\mathrm{pH}$ at $\mathrm{La} \mathrm{Paz}$ was 7.41 and $\mathrm{PCO}_{2}$ was 31.3 Torr in natives breathing air at rest, barely different from our data at $5,260 \mathrm{~m}$.

Zhuang et al. (23) showed that, at 3,658 m, highaltitude natives in Tibet also have a resting arterial $\mathrm{pH}$ of 7.40 and $\mathrm{PCO}_{2}$ of 30 Torr. They additionally assessed lowlanders who had been at $3,658 \mathrm{~m}$ for 1-2 $\mathrm{yr}$ and found $\mathrm{pH}$ to be 7.45 , with arterial $\mathrm{PCO}_{2}$ at 28 Torr. Why were the lowlanders in both the present study and that of Zhuang hyperventilating to maintain $\mathrm{pH}$ at $7.45-7.48$ after 9 wk to $2 \mathrm{yr}$ at altitude? Acute hyperventilation associated with catheterization or the mouthpiece is a possibility but seems unlikely. Our lowlanders were young Danish students used to mouthpieces, catheters, and research studies, whereas for the natives this was a completely new experience, especially catheter placement, blood sampling, breathing on a mouthpiece, and being subjected to additional acute hypoxia. If anything, acute hyperventilation would have been expected in the natives, the opposite of what was observed. Moreover, Zhuang et al. (22) 
found that arterial saturation was unaffected by presence of a mouthpiece. A second possibility is that the classical Rahn and Otis (13) line depicting alveolar $\mathrm{PO}_{2}$ and $\mathrm{PCO}_{2}$ in acclimatized subjects does not represent complete acclimatization, which produces even greater ventilation with more time at altitude. Plotting the lowlander data on the Rahn and Otis diagram (Fig. 5) indicates that our subjects had an alveolar $\mathrm{Po}_{2} \sim 5$ Torr higher and $\mathrm{PCO}_{2} 4$ Torr lower than expected.

This suggests a response in which the time to reach a $\mathrm{pH}$ of 7.40 increases with increasing altitude. In Operation Everest II, mean resting arterial $\mathrm{pH}$ was $7.44,7.46,7.50,7.53$, and 7.56 at altitudes equivalent to $0,4,750,6,100,7,620$, and $8,848 \mathrm{~m}$, respectively (16). Data from Grassi et al. (8) and Samaja et al. (14) show the same trend. What prevents normalization of $\mathrm{pH}$ at higher altitudes despite apparently normal renal function is obscure. It seems unlikely that, in our subjects, any progression of ventilation over the 9 wk was happening at a rate sufficient to prevent renal function from keeping pace.

Possible influence on natives of rapid ascent from $L a$ Paz to Chacaltaya. Because our equipment could not be duplicated in La Paz nor readily moved between Chacaltaya and La Paz, the natives were studied at Chacaltaya $(5,260 \mathrm{~m})$ on arrival after a 2 -h drive from $\mathrm{La}$ $\mathrm{Paz}(3,600-4,100 \mathrm{~m})$. We therefore anticipated acute hyperventilation because $\mathrm{PI}_{\mathrm{O}_{2}}$ was 20 Torr lower than in La Paz. However, despite a resting arterial $\mathrm{PO}_{2}$ of 42 Torr (saturation 77\%), $\mathrm{PCO}_{2}$ was 30 Torr and $\mathrm{pH}$ 7.43. Vincent et al.'s (17) La Paz data in similar resting subjects showed that arterial $\mathrm{Po}_{2}$ was 56 Torr (saturation estimated at about $90 \%$ ), $\mathrm{PCO}_{2}$ was 31.3 Torr, and $\mathrm{pH}$ was 7.41. Thus, despite the large drop in saturation, there was evidence of very little increase in ventilation.

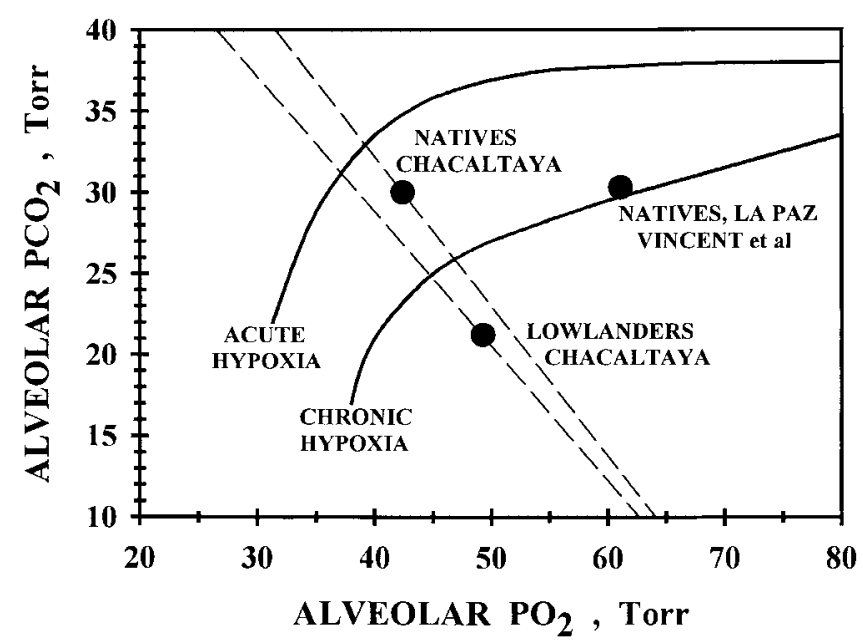

Fig. 5. Mean resting blood-gas data in lowlanders and natives plotted on a figure based on the Rahn and Otis (13) diagram. Vincent et al.'s (17) data on Bolivian natives resident at La Paz are also shown. Our native data suggest no ventilatory response to rapid ascent to $5,260 \mathrm{~m}$. Our lowlander response shows substantial departure from the data of Rahn and Otis, with lower $\mathrm{PCO}_{2}$ and higher $\mathrm{PO}_{2}$ indicating greater ventilation.
Vincent et al.'s (17) subjects fall right on the Rahn and Otis (13) line for acclimatized subjects (at 3,600 m) shown in Fig. 5 of the present paper. Rahn and Otis further showed how acute hypoxia affects alveolar $\mathrm{Po}_{2}$ and $\mathrm{PCO}_{2}$ in lowland subjects already acclimatized to various altitudes. From Fig. 5 of their paper, one estimates that $\mathrm{La} \mathrm{Paz}$ natives taken acutely to $5,260 \mathrm{~m}$ would have had an alveolar $\mathrm{Po}_{2}$ of 45-46 Torr and $\mathrm{PCO}_{2}$ of 27-28 Torr, whereas our subjects displayed values of 42 and 30 Torr, respectively.

Furthermore, because arterial saturation during constant-load exercise in each group was raised from 73 to $99 \%$ by breathing $55 \% \mathrm{O}_{2}$, the natives increased arterial $\mathrm{PCO}_{2}$ by only $6.4 \%$ (whereas lowlanders increased $\mathrm{PCO}_{2}$ by $22.8 \%$ ). These findings are compatible with the work of Schoene et al. (15), who showed that hypoxic ventilatory drive in high-altitude natives was blunted. The native responses are all the more astonishing given the low $\mathrm{O}_{2}$ saturation during exercise (Fig. 3 ) and the usual carotid body sensitivity to such hypoxemia (20).

It was feared that the acute ascent not only would represent a major ventilatory stimulus, but would also compromise exercise capacity. The outcome, however, suggests otherwise. Thus maximal cycling power output was not significantly affected: $234 \pm 6 \mathrm{~W}$ several days earlier in La Paz, compared with $217 \pm 5 \mathrm{~W}$ at Chacaltaya. The lack of significant decrease in exercise capacity with acute ascent from $3,600-4,100 \mathrm{~m}$ to $5,260 \mathrm{~m}$ is consistent with (but more dramatic than) the findings of Favier et al. (7), who in similar subjects found only a minor (8\%) decrease in $\dot{\mathrm{V}}_{2}$ max at $\mathrm{La} \mathrm{Paz}$ $(3,600 \mathrm{~m})$ between $31.4 \% \mathrm{O}_{2}$, equivalent to sea-level air, and ambient air. This insensitivity of $\dot{\mathrm{V}}_{2}$ max to $\mathrm{PI}_{\mathrm{O}_{2}}$ suggests that muscle metabolic capacity in natives has been downregulated over time in response to reduced $\mathrm{O}_{2}$ availability.

Pulmonary gas exchange during exercise. This study extends to 5,260 m the work of both Dempsey (6) at $3,100 \mathrm{~m}$ in North American high-altitude natives and Zhuang (23) at 3,658 $\mathrm{m}$ in Tibetan high-altitude natives. As in their work, a lower $(\mathrm{A}-\mathrm{a}) \mathrm{Po}_{2}$ preserves arterial $\mathrm{PO}_{2}$ and saturation at values seen in acclimatized lowlanders at the same work rate, despite the natives' higher arterial $\mathrm{PCO}_{2}$.

Because theoretical and experimental work shows that at altitude most of the $(\mathrm{A}-\mathrm{a}) \mathrm{Po}_{2}$ is due to alveolarcapillary diffusion limitation $(18,21)$, the likely basis of the lower $(\mathrm{A}-\mathrm{a}) \mathrm{PO}_{2}$ in high-altitude natives is higher diffusing capacity associated with larger lungs, as previously suggested $(15,23)$. Piiper and Scheid $(11,12)$ have shown that the degree of diffusion limitation depends on the ratio $\mathrm{DLO}_{2} /(\beta \cdot \dot{\mathrm{QT}})$, where $\mathrm{DLO}_{2}$ is the $\mathrm{O}_{2}$ diffusing capacity of the lungs, $\beta$ is the slope of the $\mathrm{O}_{2}$ dissociation curve, and $\dot{Q} \mathrm{~T}$ is cardiac output. In the present study, $\beta$ and $\dot{Q}_{\mathrm{T}}$ (Fig. 3) were similar between natives and lowlanders. The $\beta$ depends on hemoglobin concentration (similar, Table 1), in vivo $\mathrm{P}_{50}$ (similar at 31.7 and 32.0 Torr), and arterial and venous $\mathrm{Po}_{2}$ and saturation (arterial similar, Fig. 3; venous similar by calculation from $\dot{\mathrm{V}}_{2}$, cardiac output, and arterial val- 
ues, Figs. 2 and 3). Thus it is the $40 \%$ higher calculated $\mathrm{DL}_{\mathrm{O}_{2}}$ in natives that underlies the smaller $(\mathrm{A}-\mathrm{a}) \mathrm{Po}_{2}$ and preserves arterial $\mathrm{PO}_{2}$.

Cardiac output was measured by dye dilution in lowlanders and by acetylene uptake in natives. The acetylene method has been validated (2), and the cardiac output- $\mathrm{V}_{2}$ relationship was similar in the two groups (Fig. 3A), suggesting agreement. However, there may have been systematic differences between the two methods. We therefore calculated the effect of potential errors in cardiac output on estimated $\mathrm{DL}_{\mathrm{O}_{2}}$ and found that a $10 \%$ error produces a $3.4 \%$ error in the same direction in estimated $\mathrm{DL}_{\mathrm{O}_{2}}$. Thus to explain the $40 \%$ higher $\mathrm{DL}_{\mathrm{O}_{2}}$ in the natives on errors in cardiac output would require that peak cardiac output had been overestimated by $220 \%$ and was not 20 but only 9 $1 / \mathrm{min}$. This is impossible because even complete muscle $\mathrm{O}_{2}$ extraction would not have provided the measured $\dot{\mathrm{V}}_{2}$. If cardiac output in the lowlanders had been lower because of blood withdrawal during its measurement, this could have reduced estimated $\mathrm{DL}_{\mathrm{O}_{2}}$. However, each measurement requires only $20 \mathrm{ml}$ blood and moreover this was reinfused immediately. This cannot therefore explain the lower lowlander $\mathrm{DL}_{\mathrm{O}_{2}}$.

A specific assumption made in the calculation of $\mathrm{DLO}_{2}$ is that ventilation-perfusion $\left(\dot{\mathrm{V}}_{\mathrm{A}} / \dot{\mathrm{Q}}\right)$ inequality plays an insignificant role in the $(\mathrm{A}-\mathrm{a}) \mathrm{Po}_{2}$ of exercise at this altitude. Because neither group had an (A-a) $\mathrm{Po}_{2}$ at rest (Fig. 1), resting $\dot{\mathrm{V}}_{\mathrm{A}} / \dot{\mathrm{Q}}$ inequality must have been minimal. Because effects of $\dot{V}_{\mathrm{A}} / \dot{\mathrm{Q}}$ inequality on $(\mathrm{A}-\mathrm{a}) \mathrm{Po}_{2}$ lessen with increasing hypoxia, whereas those of diffusion limitation increase $(11,12,21)$, the postulate that $\dot{\mathrm{V}}_{\mathrm{A}} / \dot{\mathrm{Q}}$ inequality during exercise contributed little to the (A-a) $\mathrm{PO}_{2}$ is also reasonable. Work from Operation Everest II (18), using the multiple inert gas elimination technique to distinguish diffusion limitation from $\dot{\mathrm{V}}_{\mathrm{A}} / \dot{\mathrm{Q}}$ mismatching, confirmed that diffusion limitation was the major contributor to the $(\mathrm{A}-\mathrm{a}) \mathrm{Po}_{2}$.

Relating exercise $\mathrm{DL}_{\mathrm{O}_{2}}[119 \mathrm{ml} /(\mathrm{min} \cdot \mathrm{Torr})$, lowlanders and $167 \mathrm{ml} /(\mathrm{min} \cdot$ Torr), natives] to maximal normoxic exercise capacity ( $282 \mathrm{~W}$, lowlanders and 229 $\mathrm{W}$, natives; Table 1) provides an astonishing result: The ratio of pulmonary diffusing capacity to maximal normoxic power output is $0.73 \mathrm{ml} /(\mathrm{min} \cdot \mathrm{Torr} \cdot \mathrm{W})$ in the natives and only $0.42 \mathrm{ml} /(\mathrm{min} \cdot \mathrm{Torr} \cdot \mathrm{W})$ in the lowlanders. The natives therefore have $173 \%$ of the diffusing capacity of the lowlanders per watt of normoxic exercise capacity. It should be recalled that there were no differences in hemoglobin concentration to explain this (Table 1). This very large difference presumably stems from structural differences in their lungs. Whereas in the lowlanders (at sea level) spirometry revealed vital capacity ( $111 \%$ predicted) and resting carbon monoxide diffusing capacity (92\% predicted) that were within normal limits, vital capacity $(134 \%$ predicted Caucasian sea-level values, $P<0.01$ ) and diffusing capacity ( $142 \%$ predicted, $P<0.001$ ) were elevated in the natives when referenced to North American norms. The high $\mathrm{DL}_{\mathrm{O}_{2}}$ values in natives dur- ing exercise appear directionally compatible with these data and the literature $(6,15)$.

Acid-base balance during exercise. Despite similar blood $\mathrm{Hb}$ concentration, there appear to be acid-base control differences between the lowlanders and natives. As shown in Fig. 4, calculated base deficit rose linearly with lactate concentration in both groups, but with different slopes. The mean slope in the lowlanders $(0.97 \pm 0.02 \mathrm{meq} / \mathrm{l}$ per $\mathrm{mmol} / \mathrm{l}$ lactate $)$ is similar to values at sea level [for example, 1.03 in Operation Everest II (16) and 1.13 in the same Danish lowlanders studied later in Copenhagen] and is a reasonable (1:1) stoichiometric outcome. On the other hand, the slope in natives averaged only $0.81 \pm 0.03$, a highly significant $(P<0.001)$ difference implying greater lactate-buffering capacity. The explanation for these unexpected differences cannot be stated with certainty but may just reflect the Henderson-Hasselbalch equation: On the Davenport diagram, flattening of $\mathrm{PCO}_{2}$ isopleths occurs as $\mathrm{PCO}_{2}$ falls. Thus, at a lower $\mathrm{PCO}_{2}$, the change in $\mathrm{pH}$ ( $x$-axis) for a given change in base deficit ( $y$-axis) at constant $\mathrm{PCO}_{2}$ would be greater. The higher arterial $\mathrm{PCO}_{2}$ values in the natives (Fig. 2) are consistent with this idea. It is also possible that the natives may have had a larger blood volume, because lowlanders are known to reduce plasma volume at altitude. If this were the case, it could also have contributed to the better buffering of lactate in the natives.

Whatever the mechanism, the consequences for exercise limitation may be considerable. Recall that, at $\dot{\mathrm{V}}_{\mathrm{O}_{2} \text { max }}$ in ambient air, lactate levels were higher in the natives $(11.5 \mathrm{mmol} / \mathrm{l})$ than in the lowlanders $(8.7 \mathrm{mmol} /$ 1). Had lowlander lactate levels been as high, arterial $\mathrm{pH}$ (at the same $\mathrm{PCO}_{2}$ ) would have been 7.25 instead of 7.37 as measured. Combined with the severe hypoxemia (73\% saturation) and the evidence that ventilatory stimulation was already great $\left(\mathrm{PCO}_{2} 19\right.$ Torr, $\mathrm{pH}$ 7.37), it is likely that intolerable dyspnea would have occurred. We therefore suggest that the relatively lower buffering capacity of the lowlanders contributed to their exercise limitation.

In conclusion, this study, performed at 5,260 m, comparing Bolivian high-altitude natives resident at La Paz $(3,600-4,100 \mathrm{~m})$ to sea-level natives acclimatized for $9 \mathrm{wk}$ at 5,260 m, has demonstrated a number of pulmonary and other physiological differences between them. 1) Even 9 wk of residence at 5,260 m fails to accomplish complete normalization of arterial $\mathrm{pH}$ in lowlanders, and ventilation is greater than expected from prior data. This raises the question of whether full acclimatization at this altitude requires much longer than previously suspected, possibly lifelong or even more than one generation of exposure. 2) Reduced ventilatory response to hypoxia in high-altitude natives, both at rest and during exercise, still occurs as in previous reports at lower altitudes, despite severe acute arterial desaturation caused by rapid ascent from $\mathrm{La} \mathrm{Paz}$. 3) (A-a) $\mathrm{Po}_{2}$ values during exercise are smaller in natives likely because of increased diffusing capacity associated with larger lungs. This enables, at lower ventilatory cost, the same arterial saturation as 
in lowlanders. When related to metabolic potential assessed by maximal exercise capacity in normoxia, pulmonary diffusing capacity is $73 \%$ greater per watt in natives than in lowlanders. 4) Lactate buffering appears enhanced in natives, defending arterial $\mathrm{pH}$ in the face of both higher lactate and $\mathrm{PCO}_{2}$ levels than in acclimatized lowlanders.

We thank Professor Carlos Aguirre from the Academia Nacional de Ciencias de Bolivia and Dr. Pedro Miranda, Director of the Laboratorio de Cósmica Fisica at Chacaltaya, where the experiments were conducted, for invaluable help. The use of the facilities at the Club Andino Boliviano was most valuable and appreciated. We also thank SensorMedics for the use and support of the $\dot{\mathrm{V}}_{2}$ max system for measuring cardiac output by acetylene uptake.

This study was supported by a grant from the Danish National Research Foundation (no. 504-14). Additional funding was obtained from the Carlsberg Foundation and the Copenhagen Muscle Research Centre. J. A. L. Calbet was on leave from the Department of Physical Education at the University of Las Palmas de Gran Canaria. P. D. Wagner and H. Wagner were supported in part by National Heart, Lung, and Blood Institute Grant HL-17731.

\section{REFERENCES}

1. Andersen $\mathbf{P}$ and Saltin B. Maximal perfusion of skeletal muscle in man. J Physiol (Lond) 366: 233-249, 1985.

2. Barker RC, Hopkins SR, Kellogg N, Olfert IM, Brutsaert TD, Gavin TP, Entin PL, Rice AJ, and Wagner PD. Measurement of cardiac output during exercise by open-circuit acetylene uptake. J Appl Physiol 87: 1505-1512, 1999.

3. Boushel R, Radegran G, Calbet JAL, Sondergaard H, Wagner PD, and Saltin B. Parasympathetic neural activity accounts for the lowering of exercise heart rate at high altitude. Circulation 104: 1785-1791, 2001.

4. Cerny FC, Dempsey JA, and Reddan WG. Pulmonary gas exchange in non-native residents of high altitude. $J$ Clin Invest 52: 2993-2999, 1973.

5. DeGraff AC Jr, Grover RF, Johnson RL Jr, Hammond JW Jr, and Miller JM. Diffusing capacity of the lung in Caucasians native to 3,100 m. J Appl Physiol 29: 71-76, 1970.

6. Dempsey JA, Reddan WG, Birnbaum ML, Forster HV, Thoden JS, Grover RF, and Rankin J. Effects of acute through life-long hypoxic exposure on exercise pulmonary gas exchange. Respir Physiol 13: 62-89, 1971.

7. Favier R, Spielvogel H, Desplanches D, Ferretti G, Kayser B, and Hoppeler H. Maximal exercise performance in chronic hypoxia and acute normoxia in high-altitude natives. $J$ Appl Physiol 78: 1868-1874, 1995.

8. Grassi B, Marzorati M, Kayser B, Bordini M, Colombini A, Conti M, Marconi C, and Cerretelli P. Peak blood lactate and blood lactate vs. workload during acclimatization to 5,050 $\mathrm{m}$ and in deacclimatization. J Appl Physiol 80: 685-692, 1996.

9. Hurtado A. Animals in high altitudes: resident man. In: Adaptation to the Environment, edited by Dill. Washington, DC: Am. Physiol. Soc., 1964, p. 843-860.

10. Jibelian G, Mitchell RR, and Overland ES. Influence of hematocrit and temperature on solubility of acetylene and dimethyl ether. J Appl Physiol 51: 1357-1361, 1981.

11. Piiper J and Scheid P. Model for capillary-alveolar equilibration with special reference to $\mathrm{O}_{2}$ uptake in hypoxia. Respir Physiol 46: 193-208, 1981.

12. Piiper $\mathbf{J}$ and Scheid $\mathbf{P}$. Comparison of diffusion and perfusion limitations in alveolar gas exchange. Respir Physiol 51: 287290, 1983.

13. Rahn $\mathbf{H}$ and Otis AB. Man's respiratory response during and after acclimatization to high altitude. Am J Physiol 157: 445462, 1949.

14. Samaja M, Mariani C, Prestini A, and Cerretelli P. Acidbase balance and $\mathrm{O}_{2}$ transport at high altitude. Acta Physiol Scand 159: 249-256, 1997.

15. Schoene RB, Roach RC, Lahiri S, Peters RM Jr, Hackett $\mathbf{P H}$, and Santolaya R. Increased diffusion capacity maintains arterial saturation during exercise in the Quechua Indians of Chilean altiplano. Amer J Human Biol 2: 663-668, 1990.

16. Sutton JR, Reeves JT, Wagner PD, Groves BM, Cymerman A, Malconian MK, Rock PB, Young PM, Walter SD, and Houston CS. Operation Everest II: oxygen transport during exercise at extreme simulated altitude. J Appl Physiol 64: 13091321,1988

17. Vincent J, Hellot MF, Vargas E, Gautier H, Pasquis $P$, and LeFrancois R. Pulmonary gas exchange, diffusing capacity in natives and newcomers to high altitude. Respir Physiol 34: 219-231, 1978.

18. Wagner PD, Sutton JR, Reeves JT, Cymerman A, Groves BM, and Malconian MK. Operation Everest II: pulmonary gas exchange during a simulated ascent of Mt. Everest. $J$ Appl Physiol 63: 2348-2359, 1987.

19. Wagner PD and West JB. Effects of diffusion impairment on $\mathrm{O}_{2}$ and $\mathrm{CO}_{2}$ time courses in pulmonary capillaries. $J \mathrm{Appl}$ Physiol 33: 62-71, 1972.

20. West JB. Respiratory Physiology: The Essentials. Baltimore, MD: Lippincott Williams \& Wilkins, 2000.

21. West JB and Wagner PD. Predicted gas exchange on the summit of Mt. Everest. Respir Physiol 42: 1-16, 1980.

22. Zhuang J, Droma T, Sun S, Janes C, McCullough RE, McCullough RG, Cymerman A, Huang SY, Reeves JT, and Moore LG. Hypoxic ventilatory responsiveness in Tibetan compared with Han residents of 3,658 m. J Appl Physiol 74: 303311, 1993.

23. Zhuang J, Droma T, Sutton JR, Groves BM, McCullough RE, McCullough RG, Sun S, and Moore LG. Smaller alveolar-arterial $\mathrm{O}_{2}$ gradients in Tibetan than Han residents of Lhasa (3,658 m). Respir Physiol 103: 75-82, 1996. 